Should this important book go into a second edition, the author will have a chance to make a few small corrections. In a book entitled History of the Hour, it is embarrassing to have the origin of the hour erroneously placed in Babylon instead of in the very different astronomical culture of ancient Egypt. The translation from the German reads quite well, but in a book that often uses both 'canon' and cannon', no doubt the frequent misspelling of 'cannon' arises from the similarity in German of Kanon (canon) and Kanone (cannon).

There is a considerable muddle in the final chapter where the German Meile is repeatedly translated as "mile" instead of "league". In one instance the correct reading of 764 kilometres in the German has been altered so that the English sentence, describing the speed of post riders, reads: "One hundred and thirty-two hours were needed for 103 miles (164 kilo-metres)."

These quibbles aside, Dohrn-van Rossum has produced a persuasive and brilliantly documented new understanding of how modern time-consciousness arose.

Owen Gingerich is at the HarvardSmithsonian Center for Astrophysics, 60 Garden Street, Cambridge, Massachusetts 02138, USA.

\section{The need to love technology}

\author{
Wiebe E. Bijker
}

Aramis, or the Love of Technology. By Bruno Latour. Harvard University Press: 1996. Pp. 314. \$45, £29.95 (hbk); \$1995, £13.50 (pbk).

ARAmIS was to have been a fully automated, personal rapid transit system for Paris, combining the advantages of the car (individual, comfortable, point-to-point transportation without changing vehicles) with those of the train (no traffic jams and less pollution, yet accessible to everyone). But it is no more. So who killed it?

The first vehicles ran on a test track in 1987, and a review commission concluded that the system "could be brought to a level of technological realization" and that there was a market for it. But the project was cancelled abruptly, at a cost of 17 years of research and millions of francs. There was no scandal in the press, no bitter accusations between the contract partners and no political heads rolled. Nevertheless, all parties come under suspicion in this whodunnit - the French company Matra, because it was perhaps more interested in investing its resources in the Lille metro; the Matra engineers, because the project was never really technically feasible; the Parisian public transport agency RATP, because the vehicles had seats but no standing room, so passengers could not be squeezed in during rush hours; the budget office of the French ministry of finance, because Aramis was too expensive; and the intended passengers, because they were frightened to lose the anonymity of the Metro.

Immediately after the project ended, Bruno Latour was asked by the RATP to investigate what went wrong. On the basis of a detailed empirical study, he has written three books in one: a detective novel, in which a sociology professor and a young engineer play the parts of Sherlock Holmes and Dr Watson; a scholarly treatise introducing the modern sociology of technology; and a reproduction of original archival documents. As the book develops, we hear the voice of technology itself, with Frankenstein's "humachine" and Aramis himself as spokespersons.

The young engineer's initiation into the sociology of technology begins with the demise of all of his standard explanations for the failure of Aramis - that it was technically unfeasible, that there was no market for it, that it was too expensive, and that it had insufficient political backing. On each and every point, his professor produces documents and interview excerpts that show exactly the opposite. Even more important is another act of debunking: technology is not something cold, nonhuman and antisocial. Technology is to be "loved", for its own sake and as a basic constituent of modern society and human affairs. (Here 'love' does not mean 'adore', or even 'evaluate positively', but rather 'engage in'.) This serves as a prelude to Latour's final conclusion that an isolated technology is doomed.

In the sociological treatise, this line of analysis is characterized as symmetrical and relativist. It is symmetrical in that successful and failing outcomes are treated in the same manner; only by such a symmetrical analysis can we hope to gain an understanding that does more than "flatter the victors of the day" and provide a comfortable conclusion "at the end of the road, when we've settled down by the fire". And it is relativist because it assumes that nothing exists independently of what the actors do; that there are no fixed frames of reference; "actors never swim twice in the same river". So the economics of the project and the country, the consumer demand, the technology's intrinsic safety and the project's political support all need to be constructed continuously by the actors.

The young engineer and his professor discuss the details of the technology when investigating the last phase of the project. In a passage as hilarious as it is perceptive, the two investigators take on the roles of the software components of Aramis. This allows the engineer to get on top of the matter, and observe that his supervisor "lost his grip and could no longer write any 'sociological commentary,' as he pompously called it, on what we were discovering". The professor suffers a nervous breakdown and the student must finish the report himself.

This breakdown is symbolic of the role that Latour denies to theoretical explanations and generalization beyond one case study: "I'm not looking for anything else [than] a refined sociology which applies to a single case, to Aramis and only Aramis. A single explanation, for a single, unique case; then we'll trash it", his professor had remarked long before the breakdown. Detailed accounts of all the network building, the negotiations, the constructive work by engineers, politicians, managers and passengers are all that his relationist sociology offers, he claims: "there are as many theories of action as there are actors". This is a case of feigned modesty, probably for pedagogical reasons to chastise classical sociology.

Latour's book does offer important insights into the sociotechnical domain and engineering practices that transcend the Aramis case. It also provides, mainly in the form of methodological discussions, the groundwork for a theory of technology and society. This important asset, of what I think is Latour's best book so far, is not diminished by his obvious difficulty in reconciling his aversion to sweeping reductionist concepts with his urge to contribute to a general understanding of technology. The next challenge is to develop such a theory without falling into the trap of $a$ priori fixed categories and losing the newly won insights from detailed analysis of technological projects.

So who did kill Aramis? After studying one of the last documents of October 1987 , our young engineer suddenly finds the solution and can deliver his masterpiece: "The report presented the 1987 Aramis, word for word, as identical to [the] 1970 Aramis. I myself had found twenty-one interpretations, but the technological documents remained mute about this dispersion. Aramis had not incorporated any of the transformations of its environment. It had remained purely an object. Remote from the social arena, remote from history." Aramis had, in the end, been left intact, untouched, unmodified, unloved. Nobody had loved it enough to make it grow and develop. All parties were guilty-as a true reflection of another train murder, on the Orient Express.

Wiebe E. Bijker is in the Department of Technology and Society Studies, Rijksuniversiteit Limburg, 6200 MD Maastricht, The Netherlands. 